\title{
Prediction of Nickel Removal using Diffusion Model in Flat Sheet Supported Liquid Membrane
}

\author{
Raja Norimie Raja Sulaiman ${ }^{a, b}$, Norasikin Othman ${ }^{a, b, *}, K_{i s s a n}$ Vithilingam $^{a}$ \\ a School of Chemical and Energy Engineering, Faculty of Engineering, Universiti \\ Teknologi Malaysia, Skudai, Johor Bahru, Johor 81310, Malaysia; ${ }^{b}$ Centre of Lipids \\ Engineering and Applied Research (CLEAR), Ibnu Sina Institute for Scientific and \\ Industrial Research, Universiti Teknologi Malaysia, Skudai, Johor Bahru, Johor \\ 81310, Malaysia
}

Abstract Supported liquid membrane (SLM) is one of the potential extraction methods for the treatment of wastewater containing various toxic heavy metal ions. Advantageously, this process offers simultaneous removal and recovery, as well as low energy consumption and operational cost. In this study, the prediction of nickel removal was investigated using a diffusion model developed through MATLAB. The diffusion model was validated using previous experimental data from SLM experiments. Experimentally, the liquid membrane (LM) solution composed of di-2ethylhexyl phosphoric acid (D2EHPA) and octanol in palm oil, which were immersed in the pores of polyvinylidene fluoride (PVDF) support. The porosity, thickness, and pore size of PVDF are $75 \%, 125 \mu \mathrm{m}$, and $0.22 \mu \mathrm{m}$, respectively. Factors influencing SLM extraction of nickel were investigated, including the initial nickel concentration in the feed phase and the composition of palm oil in the organic LM phase. The permeability, mass transfer, and flux of nickel extraction were also determined. The results showed that $100 \mathrm{ppm}$ of initial nickel concentration in the feed phase with $10 \%$ palm oil composition in LM provided the highest extraction performance with maximum permeability, mass transfer, and flux of $1.36 \times 10^{-3} \mathrm{cms}^{-1}, 1.02 \times 10^{-3} \mathrm{cms}^{-1}$, and $9.75 \times$ $10^{-10} \mathrm{~mol} \mathrm{~cm}^{-2} \mathrm{~s}^{-1}$, respectively. Additionally, the permeability values showed a good correlation with the mass transfer values. The experimental and predicted values are in agreement with the regression value, $R^{2}>0.9$, thus confirming the validity of the model. Hence, it can be concluded that the modified diffusion model is feasible to predict nickel extraction in SLM.

Keywords: Supported liquid membrane, carrier, permeability, diffusion model.

*For correspondence: norasikin@cheme.utm.my

Received: 29 June 2021 Accepted: 18 Nov 2021

(C) Copyright Sulaiman et al. This article is distributed under the terms of the Creative Commons Attribution License, which permits unrestricted use and redistribution provided that the original author and source are credited.

\section{Introduction}

In the electroplating industry, nickel is one of the most valuable metals due to its superior ductility, corrosion resistance, and hardness. During electroplating, approximately $240-300 \mathrm{~g} / \mathrm{L}$ of nickel sulfate is used; subsequently, about $0.65 \mathrm{~g} / \mathrm{L}$ of nickel is discharged into the wastewater [1-2]. Referring to the Department of Environment (DOE) of Malaysia, the standard discharge of nickel from industries is 0.20 $\mathrm{mg} / \mathrm{L}$ only [3]. As the emission of nickel from industries sometimes exceeds the predetermined level, the removal of nickel from wastewater is essential. Moreover, the presence of nickel in the effluent can create the toxicity effect toward aquatic life. Several separation methods have been practiced for the removal of nickel from industrial wastewater. For instance, solvent extraction provides the extraction and stripping of nickel but not in a single stage and the process consumes a high amount of chemicals [4]. Besides, adsorption is an expensive method due to the consumption of costly adsorbents, especially activated carbon [5]. One of the successful methods to remove this toxic metal from the environment is liquid membrane (LM) technology. Three types of LM are emulsion liquid membrane (ELM), bulk liquid 
membrane (BLM), and supported liquid membrane (SLM) [6]. Similar to other types of LM, SLM offers simultaneous removal and recovery processes, low chemical consumption, and easy to operate. Flat sheet supported liquid membrane (FSSLM) is one of the popular configurations of SLM that have been applied for the removal of various heavy metals from industrial wastewater [7]. FSSLM involves the impregnation of liquid membrane solution containing extractant in solvent into the thin microporous solid support. The membrane support is clamped using a gasket, thus forming two compartments, as shown in Figure 1. One compartment represents the feed solution and the other compartment is the stripping solution. Both phases are stirred by mechanical stirrers to reduce the effect of polarization. LM solution facilitates the transportation of the desired solute, which is governed by its solubility in the membrane. The solute permeates due to the chemical potential gradient or driving force between the feed and stripping sides. The solute ion forms a complex with the extractant at the interface and diffuses to the stripping phase across the LM phase [8]. Petroleum-based organic solvent like kerosene is usually used in an SLM system, which is not highly recommended due to safety and environmental risks [1]. Previous work has found that the incorporation of green diluent in SLM, such as palm oil, resulted in a sustainable LM process [9].

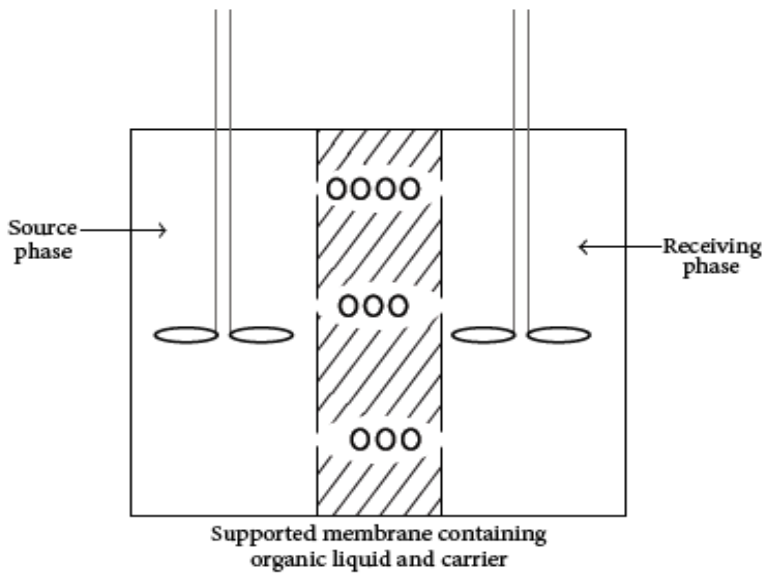

Figure 1. Schematic diagram of flat sheet supported liquid membrane (FSSLM) in membrane separation process [7].

Regarding the SLM process, theoretical and mathematical modeling is applied based on mass transfer laws [10]. Prior work has studied the SLM models involving diffusion parameters, such as transport resistances due to membrane diffusion, transport resistances due to aqueous boundary layer diffusion, aqueous diffusion layer thickness, and the solute-carrier complex diffusion coefficient through the membrane [11]. The optimal mass transfer of the solute through the SLM is influenced by many parameters. Generally, physical parameters affect the rate of solute ion diffusion through the SLM, while chemical parameters affect the chemical reactions with their respective kinetic constraints, enabling selective transport through the SLM [9]. In order to study the effect of different parameters, a developed diffusion model has been used to reduce the total number of experiments as the time usage [10]. The main objective of this work is to study nickel diffusion performance using the diffusion model developed for SLM extraction of nickel. It is due to the significance application of supported liquid membrane (SLM) in wastewater treatment cannot be observed due to insufficient theoretical information [12]. However, through modelling, the scientific data shows that the diffusion of solute across SLM is possible which provides adequate hypothetical data regarding the dynamic of extraction across SLM. Additionally, it also offers a better vision in the kinetics of extraction and separation process in this advanced technology [13]. The diffusion model was modified based on the model developed by Tan et al. [14] using MATLAB R2016b. The modified model was developed and validated using previous experimental results by Sulaiman et al. [1]. In order to validate the feasibility of the diffusion model, a comparison was made between the simulation and experimental results. Two parameters were investigated for the experiment, namely the effect of different initial nickel concentrations in the feed phase and the composition of palm oil in the liquid membrane phase. 


\section{Materials and Methods}

Electroless nickel plating (ENP) wastewater was supplied by one of the company in Senai and analysed using atomic absorption spectrometry (AAS) as shown in Table 1 [1]. Sulfuric acid $\left(\mathrm{H}_{2} \mathrm{SO}_{4}\right)(96 \%$ purity), bis (2-ethylhexyl) phosphate (D2EHPA, 95\% purity), octanol (99\% purity) and kerosene were acquired by Merck. Palm oil was obtained from local market. Polyvinylidene fluoride (PVDF) with $125 \mu \mathrm{m}$ of thickness, $75 \%$ of porosity and $0.22 \mu \mathrm{m}$ of pore size was supplied by Millipore.

Table 1. Electroless nickel plating (ENP) wastewater characterization [1].

\begin{tabular}{cccc}
\hline Cation & Concentration $(\mathrm{ppm})$ & Anion & Concentration $(\mathrm{ppm})$ \\
\hline Sodium, $\mathrm{Na}$ & 34060 & Fluoride, $\mathrm{F}$ & 10140 \\
Ammonium, $\mathrm{NH}_{4}$ & 17220 & Chloride, $\mathrm{Cl}$ & 13 \\
Potassium, $\mathrm{K}$ & 79 & ${\text { Phosphate, } \mathrm{PO}_{4}}$ & 56144 \\
Calcium, $\mathrm{Ca}$ & 16 & ${\text { Sulfate, } \mathrm{SO}_{4}}_{30410}$ \\
\hline
\end{tabular}

Figure 2 displays the flowchart of this work wherein the diffusion model was created using MATLAB $\mathrm{R} 2016 \mathrm{~b}$ to forecast the simulation outcome. The interfacial fluxes and extraction equilibrium constant were used to create the diffusion model. SLM extraction of nickel was performed to produce the experimental result for model validation. Two parameters investigated were initial nickel ion concentration in the feed phase and composition of palm oil in the membrane phase. The model's practicality was tested by comparing the both the simulation and experimental data. In addition, the flow, permeability, mass transfer coefficient, and extraction were estimated.

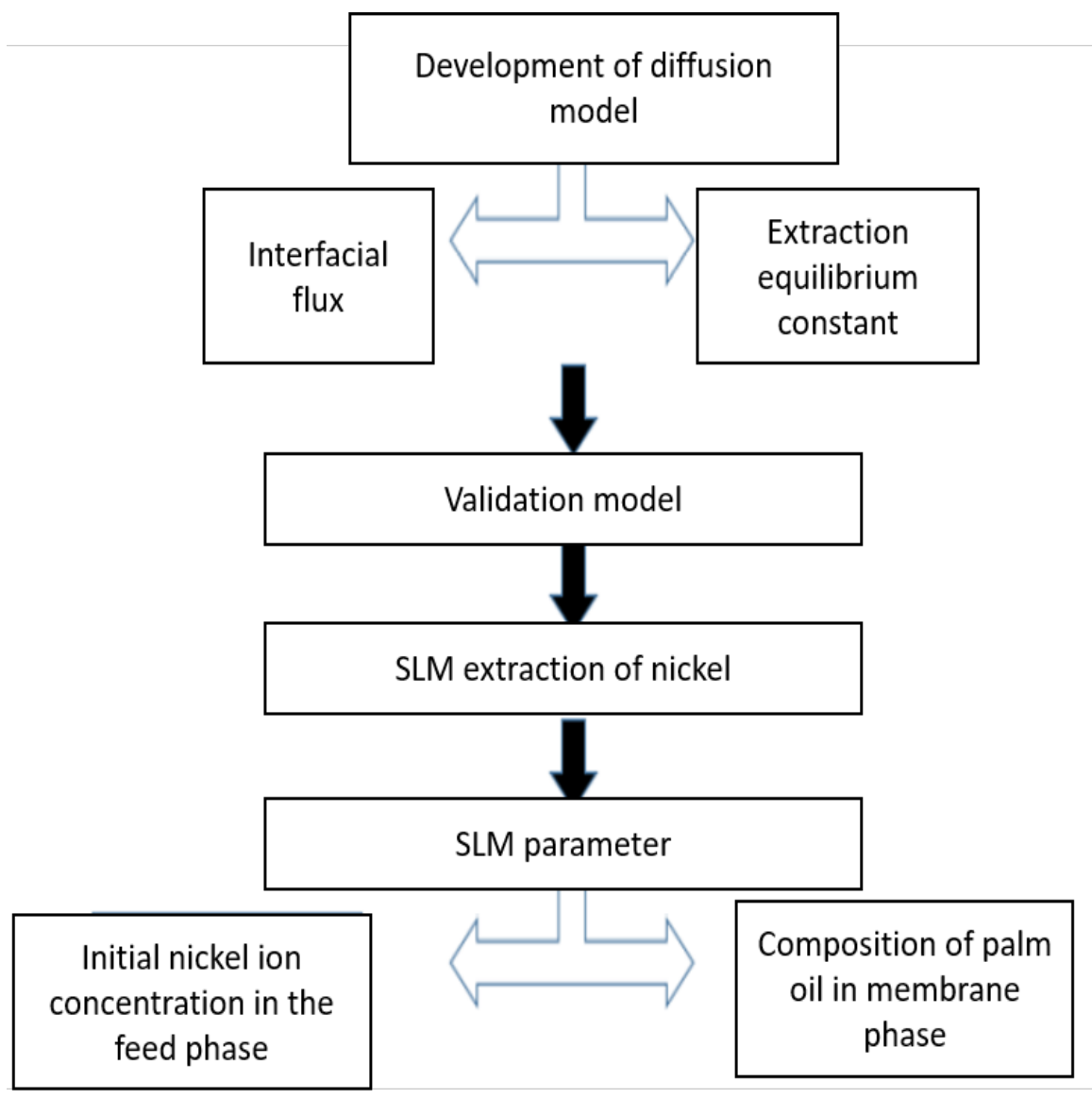

Figure 2. Flowchart of the work. 


\section{Development of diffusion model}

Fundamentally, at the feed-membrane interface, the solute ion diffuses through the aqueous feed boundary layer and reacts with the carrier, which is positioned in the pores of the membrane support, generating a solute-carrier complex species. Due to the negative concentration gradient, the complex diffuses through the liquid membrane phase to the stripping phase. Finally, at the membrane-stripping interface, the solute-carrier complex releases the solute ion in the aqueous stripping solution [15]. Figure 3 depicts the mass transfer of nickel in SLM using the following procedures [15-16]:

i. Diffusion of nickel ion from the bulk of the feed phase, $[N i]_{B f}$, to the diffusion layer of aqueous feed phase.

ii. Complexation reaction between nickel ions, $[\mathrm{Ni}]_{B f}$, and carrier at the feed-membrane interface.

iii. Diffusion of nickel-carrier complex, $\left(\operatorname{NiR}\left(R-H O R^{\prime}\right)_{i, f}\right.$ through the liquid membrane phase towards membrane-stripping interface.

iv. Upon reaching at the membrane-stripping interface, the nickel ion from the loaded nickelcarrier complex, $\left(\mathrm{NiR}\left(\mathrm{R}-\mathrm{HOR}^{\prime}\right)_{i, s}\right.$ are liberated into the stripping phase $\left([\mathrm{Ni}]_{i, s}\right)$ through the cation exchange mechanism with the hydrogen ions from the sulfuric acid solution.

v. Diffusion of stripped nickel ion to the bulk of the stripping solution, $[\mathrm{Ni}]_{B S}$

vi. Diffusion of regenerated carrier through the liquid membrane phase to the feed-membrane interface since the carrier molecules provide low solubility in the aqueous phase.

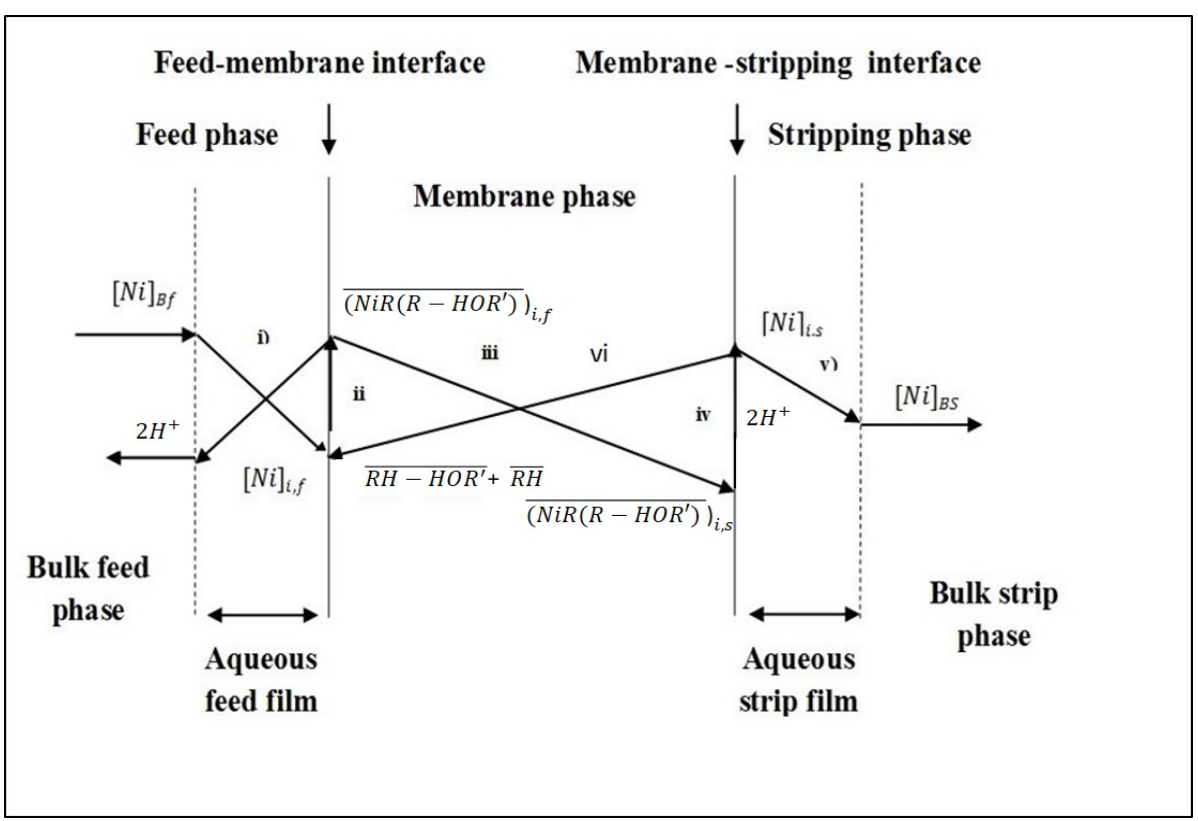

Figure 3. Membrane transport profile of nickel ion through SLM [17].

Interfacial chemical reactions at the feed-membrane and membrane-stripping interfaces are intrinsically rapid, thus they are assumed to be negligible and being ignored. Besides, the mass transfer of the solute ion penetrates through the liquid membrane phase only considering the diffusional characteristics [16]. As a result, the diffusion rate of nickel ions via the feed diffusion layer and the diffusion rate of nickelcarrier complexes across the liquid membrane phase govern the nickel ion transport rate. The flow of nickel through the liquid membrane phase is represented by Fick's first law at both the feed phase diffusion layer and the membrane phase diffusion layer. The diffusional flux of nickel ion from the bulk of the feed phase to the aqueous stagnant layer in the feed-membrane interface $\left(\mathrm{Jaq}_{a}\right)$, and the liquid membrane phase $\left(J_{\text {org }}\right)$ in the steady state can be described by Equations (1) and (2):

$$
J_{a q}=\Delta_{a q}^{-1}\left([A]_{B f}-[A]_{i, f}\right)
$$




$$
J_{\text {org }}=\Delta_{\text {org }}^{-1}\left(\overline{[A B}_{i, f}-\left[\overline{A B}_{i, s}\right)\right.
$$

Where $\Delta_{a q}^{-1}$ and $\Delta_{o r g}^{-1}$ are the resistances from boundary layer of feed phase and permeation across the organic LM, respectively; $[A]_{B f}$ and $\overline{[A]_{l, f}}$ are the solute ion concentrations in the feed and feed/organic LM interface, respectively; $\overline{[A B}]_{i, f}$ and $\left[\overline{A B}_{i, s}\right.$ are the concentration of the solute-extractant complex at feed/organic LM and organic LM/stripping interfaces, respectively. As distribution coefficient of solute ions among organic LM and stripping phases is lesser than the feed/organic LM phases, the soluteextractant complex concentration at the organic LM/stripping interface, $\left[\overline{A B}_{i, s}\right.$ is negligible compared with feed solution side 18-19]. Therefore, $J_{\text {org }}$ in Eq. (3) can be expressed as

$$
J_{\text {org }}=\Delta_{\text {org }}^{-1}[\overline{A B}]_{i, f}
$$

The equilibrium constant, $K e q$ can be defined as

$$
K_{e q}=\frac{[\overline{A B}]}{[A][\bar{B}]}
$$

where, $\overline{[A B}]$ signifies concentration of at the organic side of feed/membrane interface while $[A]$ is the concentration of solute at the aqueous side of feed/membrane interface. $[\bar{B}]$ represents the extractant. From the Eq. (3), the solute-extractant complexes concentration at the feed/organic LM interface, $[\overline{A B}]_{i, f}$ can be given as

$$
[\overline{A B}]_{i, f}=K_{e q}[A][\bar{B}]
$$

In view of the system at the stable state $\left(J=J_{a q}=J_{o r g}\right)$, the flux, $J$ can be expressed as

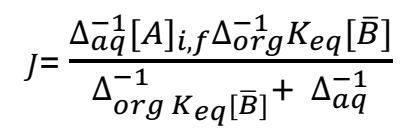

Since the permeability coefficient, $P=\frac{J}{[A]_{i, f}}$, Equation (6) was presented as

$$
P=\frac{\Delta_{a q}^{-1} \Delta_{o r g}^{-1} K_{e q}[\bar{B}]}{\Delta_{o r g}^{-1} K_{e q[\bar{B}]}+\Delta_{a q}^{-1}}
$$

The reactions process involves during nickel extraction using SLM are represented by Eqs (8) and (2) [9]. Initially, octanol destroys the dimerization of D2EHPA in the organic phase as represented by Eq. (8):

$$
(R H)_{2(o r g)}+\left(\mathrm{R}^{\prime}-\mathrm{OH}\right)_{\text {org }} \rightarrow\left(H R-H O R^{\prime}\right)_{\text {org }}+(R H)_{\text {org }}
$$

Where $(R H)_{2}$ is a dimer of D2EHPA molecules; $\left(\mathrm{R}^{\prime}-\mathrm{OH}\right)_{\text {org }}\left(\mathrm{R}^{\prime}-\mathrm{OH}\right)$ is octanol; $\left(H R-H O R^{\prime}\right)$ is a D2EHPA-octanol complexes where $R$ and $R^{\prime}=\mathrm{C}_{8} \mathrm{H}_{17}$

Then, the reaction between nickel and extractant at the organic-aqueous interface as shown in Eq. (9):

$$
N i_{a q}^{2+}+\left(H R-H O R^{\prime}\right)_{o r g}+(R H)_{o r g} \rightarrow N i R\left(R-H O R^{\prime}\right)_{o r g}+2 H^{+}(\text {aq })
$$

Based on Eq. (9), the equilibrium constant nickel, Keq was derived and given in Eq. (10), 


$$
K e q=\frac{[N i R(R-H O R)]\left[H^{+}\right]^{2+}}{\left[N i^{2+}\right]\left[H R-H O R^{\prime}\right][R H]}
$$

In order to develop a model, other equations are needed such as mass balances of species. Using organic LM to aqueous feed phase ratio $(\mathrm{O}: \mathrm{A})$ of 1 , mass balances of metal ion and extractants are shown in Eqs. (11) and (12), respectively [11, 20]]:

$$
\begin{gathered}
{[N i]_{o, i}=N i_{a q}+N i R\left(R-H O R^{\prime}\right)_{\text {org }}} \\
{[L]_{\text {total,i }}=N i R\left(R-H O R^{\prime}\right)_{\text {org }}+\left(H R-H O R^{\prime}\right)_{\text {org }}}
\end{gathered}
$$

where $[\mathrm{Ni}]_{\mathrm{o}, \mathrm{i}}$ and $[\mathrm{L}]_{\text {total,i }}$ represent the initial nickel concentration and extractant in each condition (i), respectively. It is illustrated that (i) refers to various D2EHPA concentrations (e.g., $\mathrm{i}=1$ signifies $0.1 \mathrm{M}$ D2EHPA). To formulize the equations, concentrations of $N i R\left(R-H O R^{\prime}\right)(\mathrm{org}),\left[H R-H O R^{\prime}\right]_{\text {org }}$ are signified as $x(1)$ and $x(2)$, respectively. Therefore, Eqs. (13) - (14) were revised using Eqs. (10) to (12) to be solved in the mathematical program using MATLAB $[11,20]$ :

$$
\begin{aligned}
& y(1)=x(1)-K_{e q} \times x(2) \times N i_{i f} \\
& y(2)=D 2 E H P A o-x(1)-x(2)
\end{aligned}
$$

where $N i_{i f}$ is the initial nickel concentration in the aqueous feed phase and D2EHPA $A_{o}$ is the D2EHPA concentration in the organic LM. Modeling was performed based on the Fick's law of permeation and flux equations as shown in Eq. (15).

$$
J \mathrm{Ni}=K_{\text {org }} \times N i R\left(R-H O R^{\prime}\right)_{\text {org }} \times \mu
$$

Where $J_{N i}$ is the flux of nickel permeated through the organic LM membrane, $K_{\text {org }}$ is an overall mass transfer coefficient associated to the permeation coefficient, and $\mu$ clarifies the viscosity. Eq. (16) is rewritten using Eq. (15) to solve in the mathematical program.

$$
y(3)=x(3)-K_{\text {org }} \times x(1) \times \mu
$$

Based on the previous studies, permeability, $p$ is inversely proportional to the diffusional resistance, $R$ and can be represented by Eq.(17) [21].

$$
\rho=\frac{1}{R}
$$

where

$$
R=[N i] o . i \times \mu \times c
$$

where $c$ is defined as composition of palm oil. Rearranging Eqs. (17) and (18), permeability can be represented by Eq. (19)

$$
\rho=\frac{1}{([N i] o . i \times \mu \times c)}
$$

Based on Eq. (19), permeability can be represented as y(4) in Eq. (20) in mathematical program.

$$
y(4)=\frac{1}{([N i] o . i \times \mu \times c)}
$$

$J_{N i}$ also can be represented by Eqs. (19) and (20) [16]: 


$$
\begin{aligned}
& J \mathrm{Ni}=C_{\text {exp }} \times \rho \\
& J \mathrm{Ni}=\frac{V}{S} \times \frac{d c}{d t}
\end{aligned}
$$

where $C_{\text {exp }}$ denotes the concentration of initial nickel ion in the aqueous feed phase $\left(\right.$ moldm$\left.^{-3}\right)$, p represents permeability coefficient $\left(\mathrm{cms}^{-1}\right)$ as well as $\mathrm{dc} / \mathrm{dt}$ is changes of nickel concentration towards the time changes. Meanwhile, $\mathrm{V}$ is the feed phase volume and $\mathrm{S}$ is the surface area of membrane support. Rearranging Eqs. (21) and (22), Eq. (23) was obtained.

$$
\frac{d c}{d t}=\frac{S \times C_{\text {exp }}}{([N i] o . i \times \mu \times c) \times V}
$$

The mass transfer, dm/dt can be liberated as Eq. (24).

$$
\text { Mass transfer, } \frac{d m}{d t}=\frac{d c}{d t}=\frac{S \times \operatorname{Cexp}}{([N i] o . i \times \mu \times c) \times V}
$$

All these mathematical coding has been used to develop a FSSLM model. In order to assess the validity of model, the simulation result obtained using MATLAB solver will be compared with the experimental data. Absolute relative deviation (\%AARD) is used to determine the deviation between simulated and experimental results [20]. \%AARD is calculated as following Eq. (25):

$$
A A R D(\%)=\frac{1}{N E} \sum_{i=1}^{N E}\left|\frac{(\mathrm{C}) \mathrm{i}, \exp -(\mathrm{C}) \mathrm{i}, \mathrm{calc}}{(\mathrm{C}) \mathrm{i}, \exp }\right| \times 100
$$

Where $(C)_{i, \exp }$ is the measured nickel concentration after extraction $(p p m),(C)_{i, \text { calc }}$ is the calculated nickel concentration (ppm) from the simulation and NE is the number of experimental data points.

\section{Validation of model}

The programming algorithm diagram is shown in Figure 4. Using this algorithm, MATLAB R2016b was used to code the SLM modeling. The code was run using the function of ODE45 in MATLAB R2016b to solve ordinary differential equations (ODE). The values of the parameters must be defined and inserted into the program script before coding is executed. The output results of extraction efficiency were displayed in a graph at optimum operating conditions. Lastly, the validity of the model was assessed via comparison of the results obtained from simulation and experiment. A collection of existing data from literature was used for model validation. The absolute relative deviation (AARD \%) controls the error among the simulated and experimental results.

\section{SLM extraction of nickel}

SLM rig is furnished with the membrane cell, peristaltic pump, flow meter, feed and strip vessel as displayed in Figure 5. The membrane cell is made out of two compartments produced using Teflon block. Each compartment has a flow route which assists the flow of feed and strip solution during the experiment. In SLM, the organic LM solution comprises of D2EHPA and octanol in kerosene. PVDF support was immersed with the abovementioned organic LM solution for 24 hours. After impregnation, the support was dripped for a while to wipe out all the additional organic LM solution from the surface of PVDF. Thereafter, the support was placed in the membrane cell. Around $300 \mathrm{~mL}$ of aqueous feed and stripping solutions were filled up in the vessels. Sulfuric acid solution was used as a stripping phase. During experiment, these solutions were continually stirred at $300 \mathrm{rpm}$. Around $10 \mathrm{~mL}$ of sample from feed phase were withdrawn at each 60 minutes for 6 hours and analyzed using AAS. The experiment was performed at room temperature $\left(26 \pm 1^{\circ} \mathrm{C}\right)$ with the standard deviations less than $\pm 3 \%$. Ranges of parameter studied were fixed in which the initial concentration of nickel were around 100-300ppm and composition palm oil were around $10-50 \%[1,4]$. 


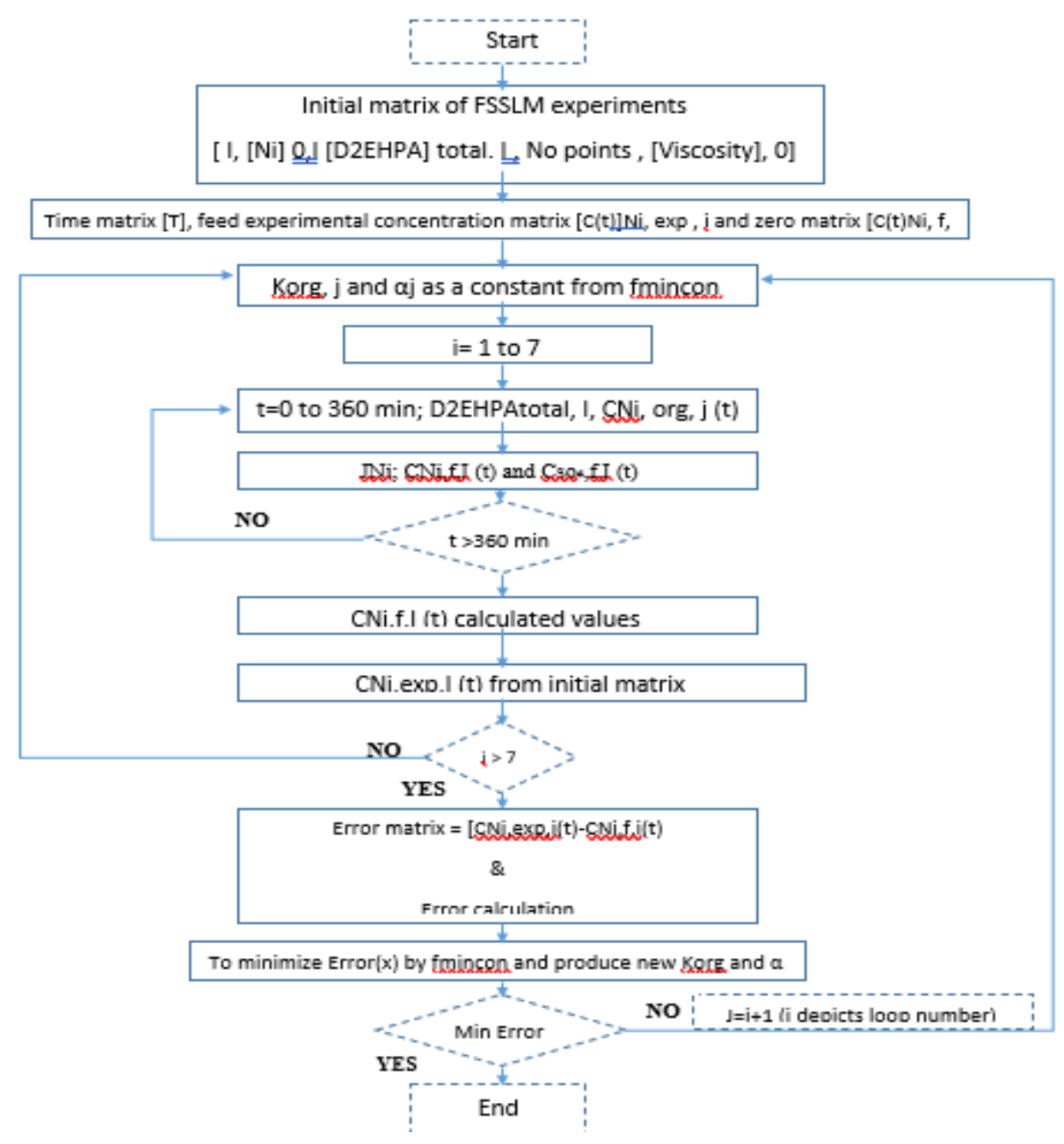

Figure 4. Algorithm for solving FFSLM modelling based on Haghighi et al. [20]. 


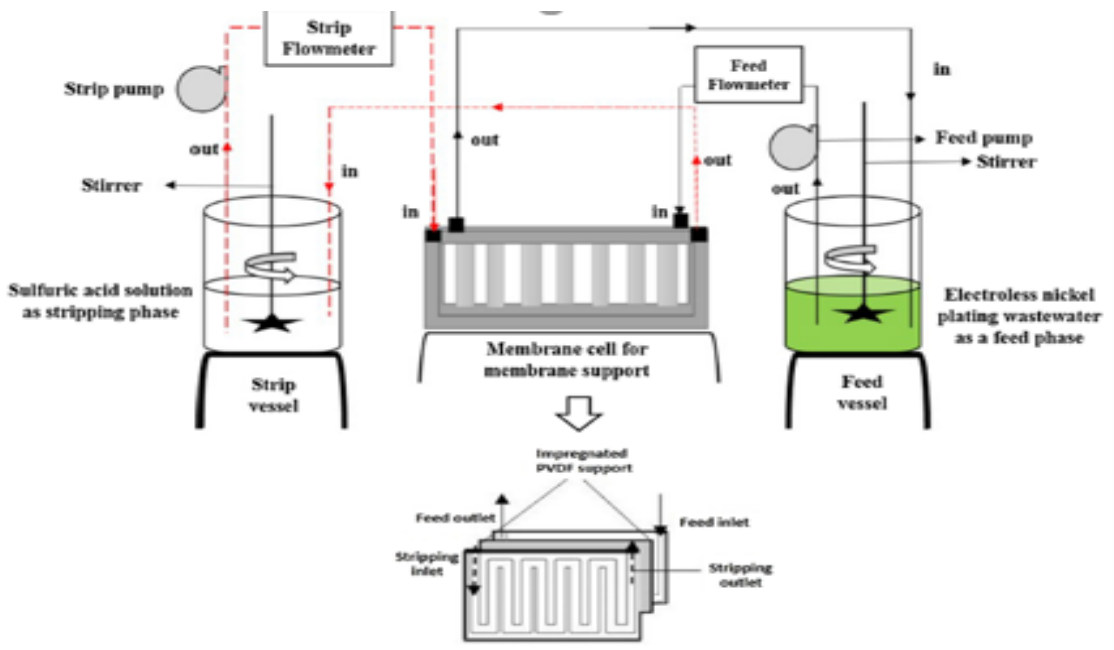

Figure 5. Schematic diagram of SLM process [1].

\section{Results and discussion}

\section{Model validation}

Figure 6 shows the model validation results for both predicted and experimental data using different initial nickel concentrations in the feed phase. As observed, the experimental data are in agreement with the simulation results. Meanwhile, the AARD \% of each range was calculated using Eq. (25). From the results, these deviation values are quite small and did not change significantly, which are $10.19 \%$, $11.80 \%$, and $9.89 \%$ for 100,200 , and 300 ppm of initial nickel concentration, respectively. The deviation might be due to the accumulation of nickel in the organic phase. During the experiment, an increment of nickel in the feed phase increases the loading capacity in the organic phase, hence saturating the organic phase. This situation decreases the mass transfer coefficient of nickel diffusion. Conversely, the saturation effect of nickel in the organic phase was not considered in the simulation work.

On the other hand, Figure 7 exhibits the results of model validation for both predicted and experimental data with respect to different compositions of palm oil in the liquid membrane phase. Similarly, the experimental results are in agreement with the simulation results. Additionally, each range studied showed small values of AARD \%, thus showing insignificant deviation between the simulation and experimental values. The deviation might be due to the viscosity effect. Sulaiman et al. [17] claimed that the viscous palm oil helps to stabilize the SLM support which inhibits the loss of the LM phase within the pores of the PVDF support. Similar observations were reported by previous studies, where the high capillary force of the viscous solvent in the membrane support could reduce the displacement of liquid membrane from the membrane support matrix [22-23]. However, the viscous palm oil resists the permeation of nickel in the organic phase. Through simulation, the accumulation of nickel as a result of viscous organic phase was not considered.

\section{Prediction of SLM parameters for nickel extraction Effect of different initial nickel concentration in the feed phase}

Figure 8 exhibits the performance of nickel extraction at various initial nickel concentrations in the feed phase. Meanwhile, Table 2 tabulates the results for the permeability, mass transfer, and flux of nickel extraction with respect to different initial nickel concentrations. As observed, the lowest initial nickel concentration of $100 \mathrm{ppm}$ offers the highest nickel extraction efficiency of $91.49 \%$. Also, the maximum permeability $\left(7.6 \times 10^{-4} \mathrm{cms}^{-1}\right)$ and mass transfer $\left(5.7 \times 10^{-4} \mathrm{cms}^{-1}\right)$ of nickel extraction were achieved at this stage. Basically, the high permeation value of nickel is controlled by the diffusion of the lower initial nickel concentration of nickel in the feed phase [24]. At the lowest initial concentration of 100 ppm, nickel ions can easily diffuse from feed to stripping phases through the liquid membrane phase. This is in agreement with Sulaiman et al. [1], who reported that at a low initial concentration, more metal ions could diffuse into the liquid membrane phase due to low mass transfer resistance at the feed-membrane 
interface. As the initial nickel concentration increased up to $300 \mathrm{ppm}$, the extraction efficiency reduced to $55.23 \%$. Likewise, the permeability and mass transfer values also decreased to $5.7 \times 10^{-4}$ and 4.3 $\times 10^{-4} \mathrm{cms}^{-1}$, respectively. Similar behavior was reported by Chakraborty et al. [25], who indicated that the extraction efficiency decreased by increasing the initial solute concentration. This situation is due to the high concentration of metal ion in the feed phase which needs more extractant for complex formation. As permeability and initial nickel concentration contradicts with the viscosity of LM, this would directly decrease the extraction efficiency of nickel [21]. This is in line with Parhi [6], who stated that the metal concentration in feed solution is inversely proportional to the viscosity of liquid membrane. This is most likely due to liquid membrane saturation, resulting in a lower effective membrane region of SLM. As the nickel ion concentration increases in the aqueous feed phase, more nickel-D2EHPA complexes are formed, resulting in the buildup of the carrier layer on the membrane interface. Subsequently, this phenomenon assists the retention of nickel on the feed-membrane interface, hence decreasing the mass transfer coefficient. Figure 9 shows the correlation of the permeability values, which seemed to be directly proportional to the mass transfer values. Such result is in accordance with Abdulrasoul et al. [21], who reported both mass transfer coefficient and permeability depend on each other.

In contrast, the flux of nickel in the LM phase augmented from $8.33 \times 10^{-10}$ to $1.88 \times 10^{-9} \mathrm{~mol} \mathrm{~cm}^{-2} \mathrm{~s}^{-1}$ as the initial nickel concentration increased from 100 to 300 ppm, respectively. It can be probably due to the flux which did not reach the plateau, that can be caused by a further increase in the initial nickel concentration in the feed phase. Such a phenomenon agrees with the Fick's first law, which states that the flux of nickel in the LM phase is in line with the concentration of the initial nickel ion in the feed phase [26]. Hence, $100 \mathrm{ppm}$ of initial nickel concentration with low diffusional resistance would be suitable for further experiment.

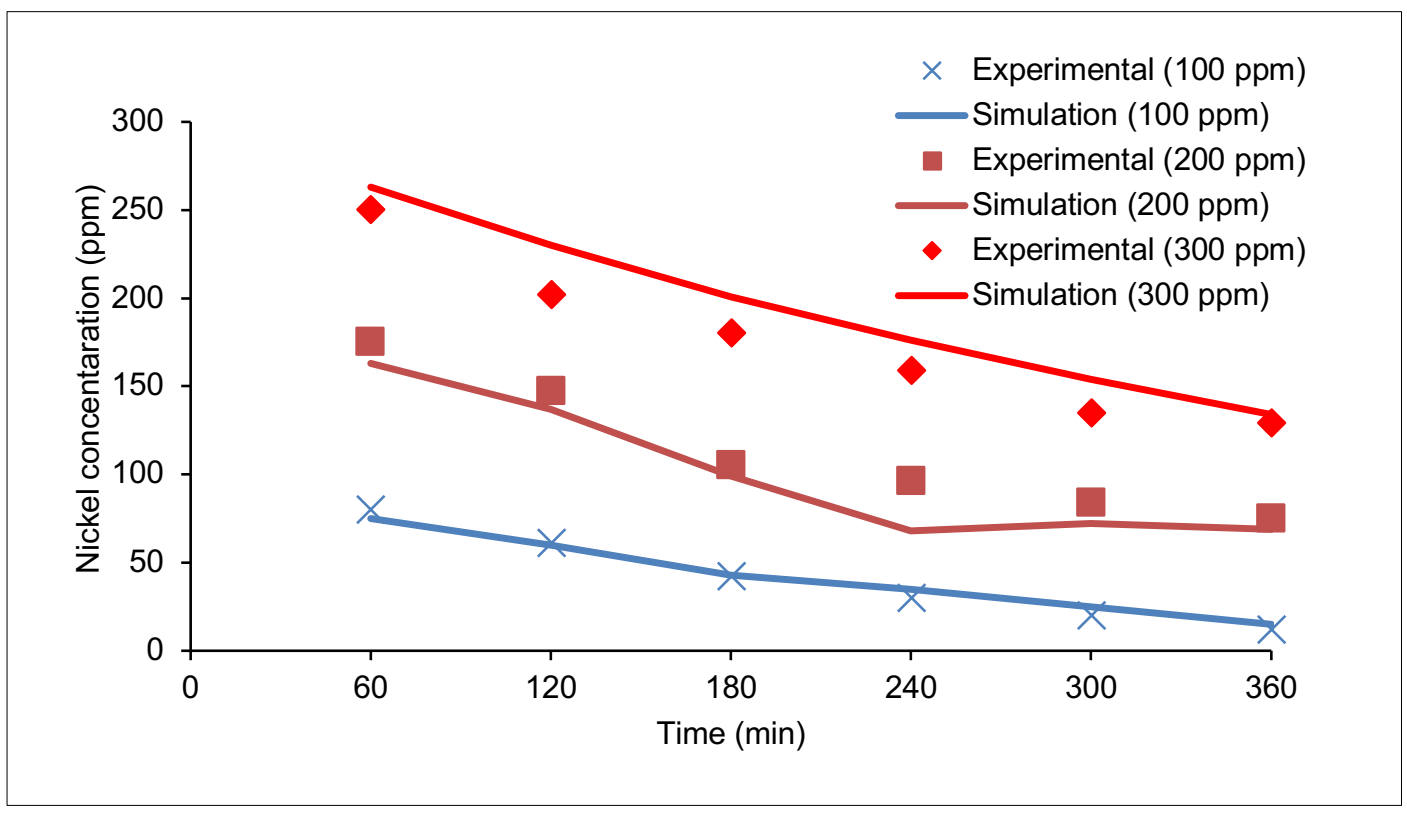

Figure 6. Comparison of simulation and experimental data with regards to (a)100 ppm (AARD:10.19\%), (b) 200 ppm (AARD:11.80\%), and (c) 300 ppm (AARD: 9.89\%) of initial nickel concentration in the feed phase. 


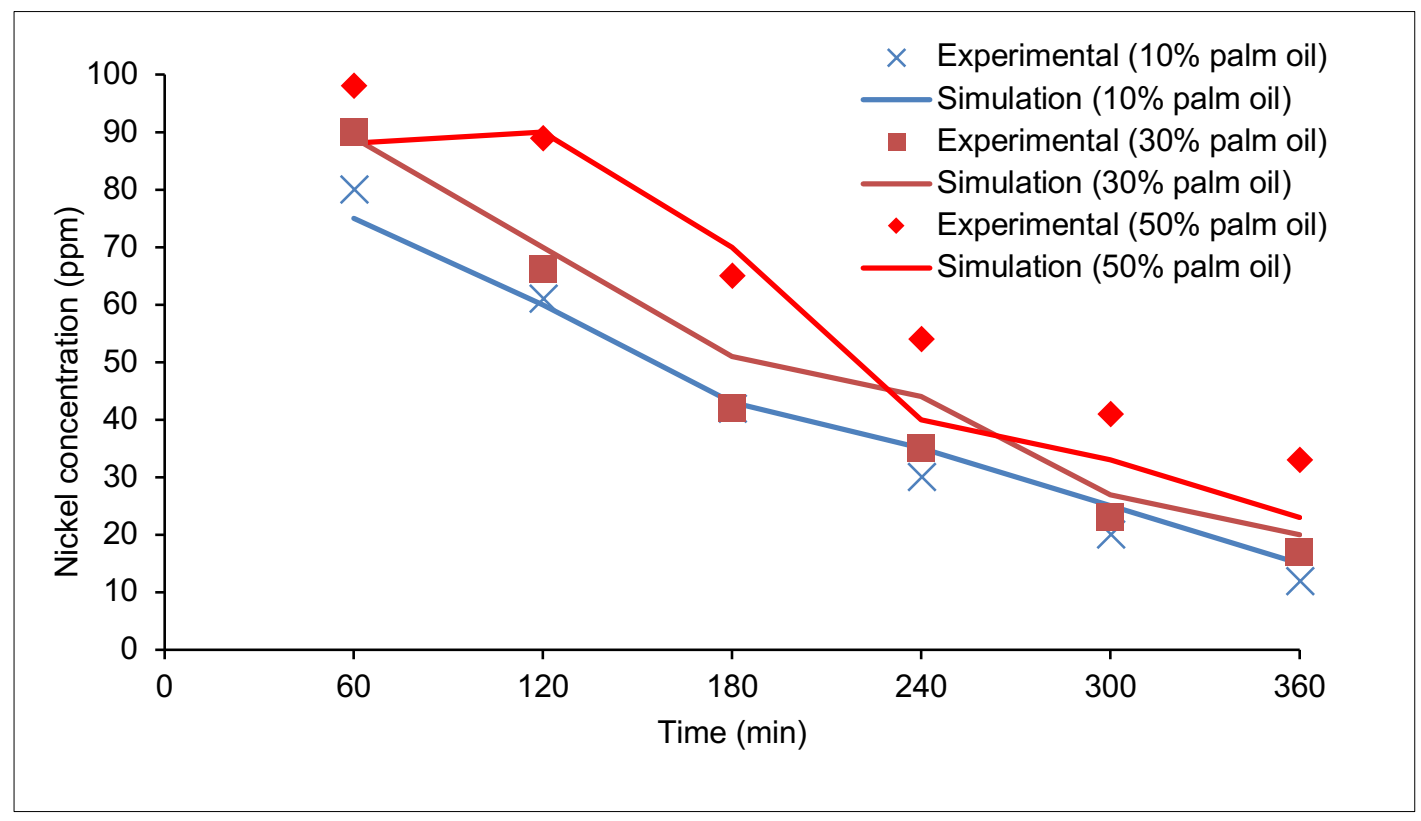

Figure 7. Comparison of simulation and experimental data with regards to a) $10 \%$ (AARD:10.19\%), (b)30\% (AARD:14.52\%), and (c) 50\% (AARD:12.85\%) of composition of palm oil in liquid membrane phase.

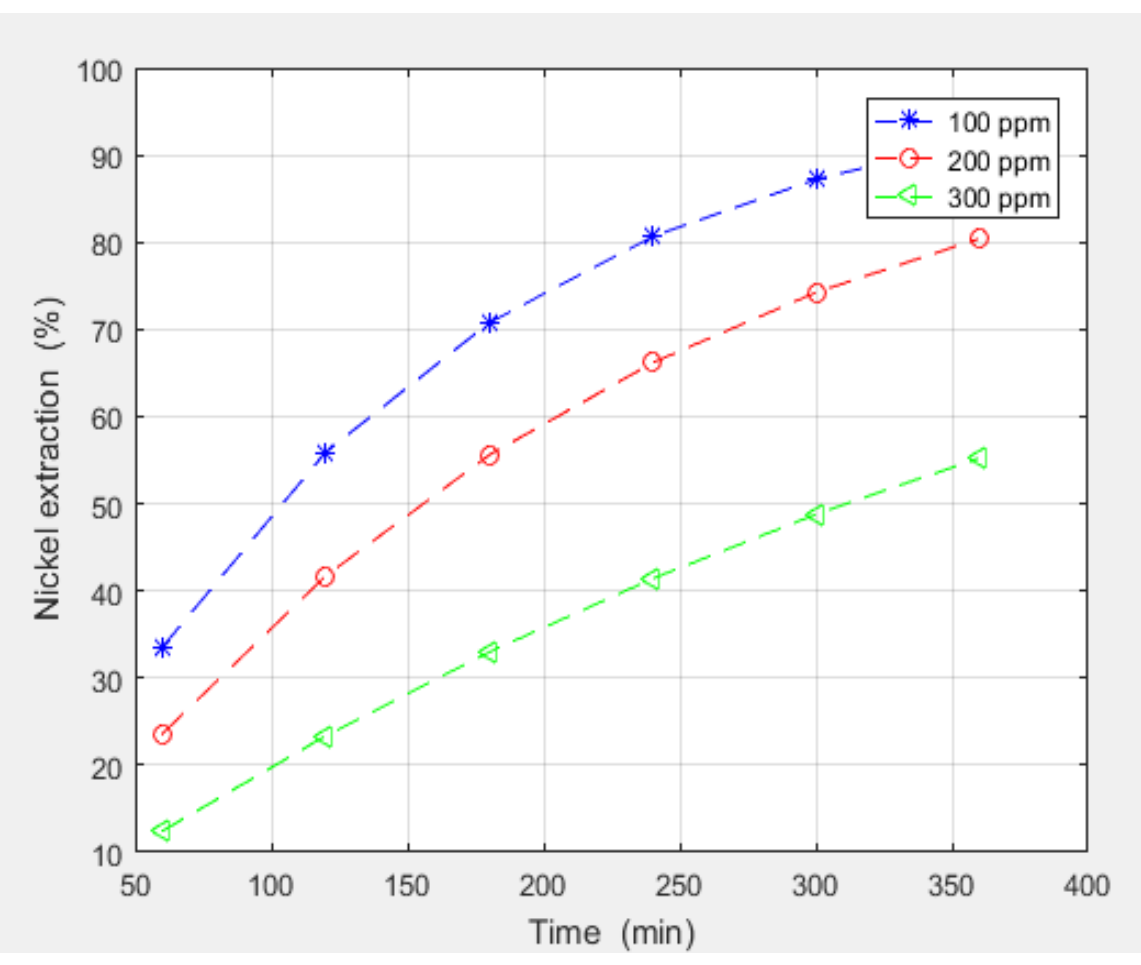

Figure 8. Nickel performance at different initial nickel concentration at feed phase. 
Table 2. Variation of permeability, mass transfer coefficient and flux with regard to the effect of different initial nickel concentration for data from diffusion model.

\begin{tabular}{llll}
\hline$[\mathrm{Ni}](\mathrm{ppm})$ & Permeability $\left(\mathrm{cms}^{-1}\right)$ & Mass transfer coefficient $\left(\mathrm{cms}^{-1}\right)$ & Flux $\left(\mathrm{molcm}^{-2} \mathrm{~s}^{-1}\right)$ \\
\hline 100 & $7.6 \times 10^{-4}$ & $5.70 \times 10^{-4}$ & $8.33 \times 10^{-10}$ \\
200 & $6.7 \times 10^{-4}$ & $5.03 \times 10^{-4}$ & $1.43 \times 10^{-9}$ \\
300 & $5.7 \times 10^{-4}$ & $4.28 \times 10^{-4}$ & $1.88 \times 10^{-9}$ \\
\hline
\end{tabular}

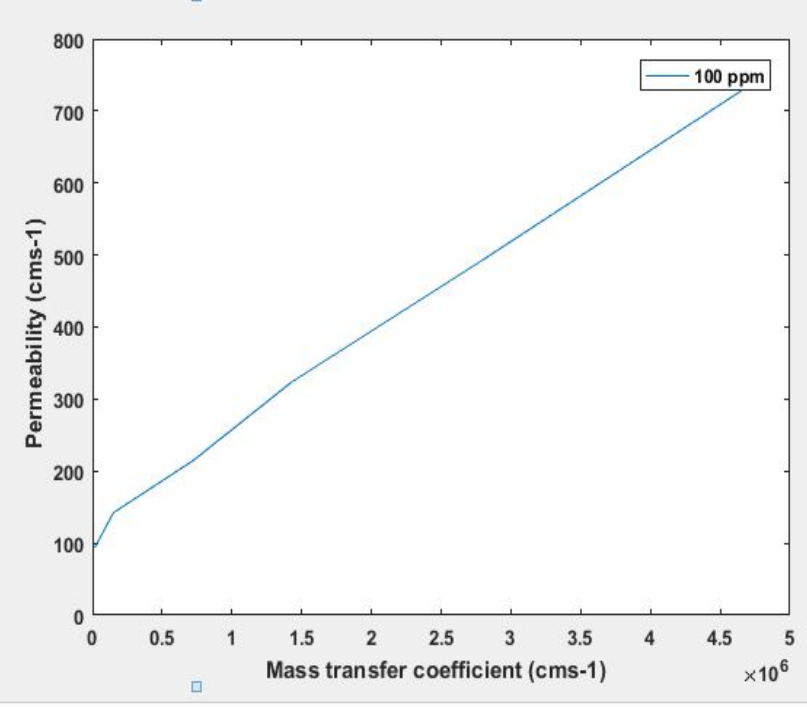

(a)

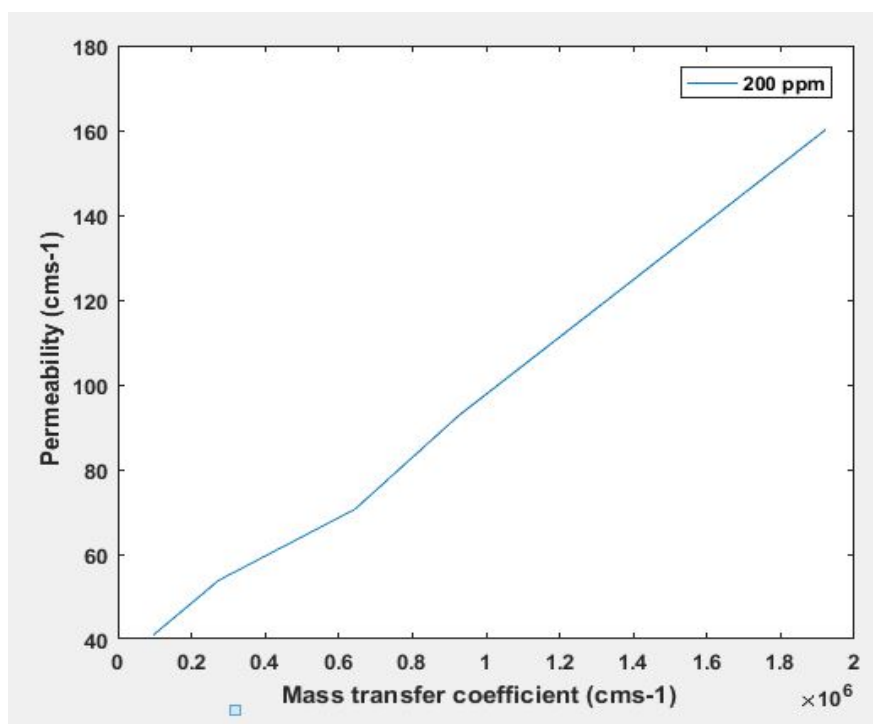

(b)

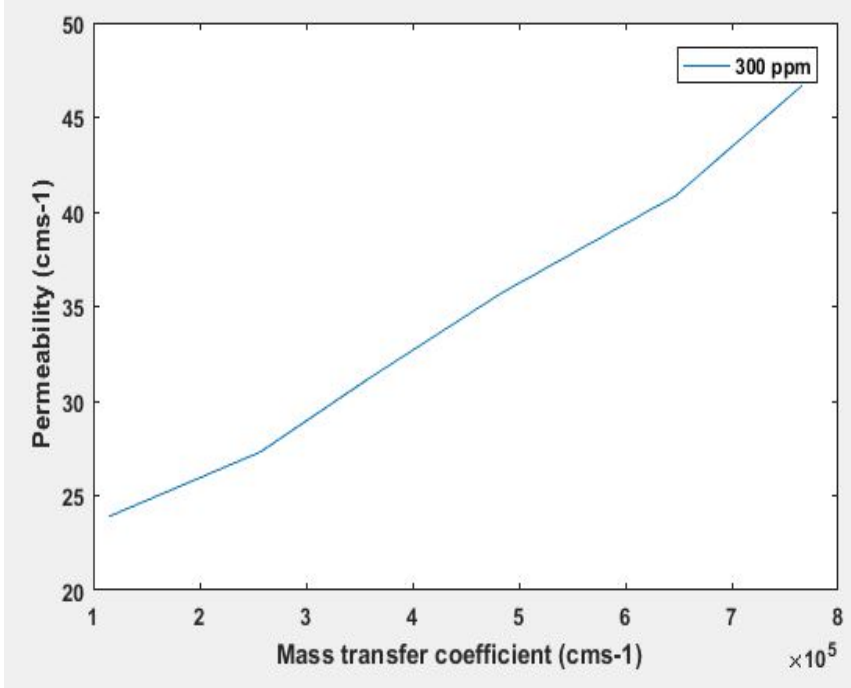

(c)

Figure 9. Correlation of permeability and mass transfer with regards to (a) $100 \mathrm{ppm}$, (b) $200 \mathrm{ppm}$ and (c) $300 \mathrm{ppm}$ of initial nickel concentrations. 


\section{Effect of different composition of palm oil in liquid membrane}

\section{phase}

Essentially, the effect of palm oil composition is regarded as one of the significant operational parameters due to the incorporation of green diluent for the removal of nickel via the SLM process. Figure 10 presents the comparison of simulation results obtained with respect to the effect of different compositions of palm oil toward nickel extraction efficiency. The variations of the viscosity, permeability, mass transfer, and flux with respect to different compositions of palm oil in the liquid membrane are tabulated in Table 3. The results depicted that the lowest palm oil composition (i.e., 10\%) provided the highest nickel extraction efficiency (59\%) with high permeability $\left(1.36 \times 10^{-4} \mathrm{cms}^{-1}\right)$ and mass transfer $\left(1.02 \times 10^{-3} \mathrm{cms}^{-}\right.$ $\left.{ }^{1}\right)$ of nickel extraction. However, as the palm oil composition increased from 30 to $50 \%$, the permeability $\left(1.19 \times 10^{-4} \mathrm{cms}^{-1}\right)$ and mass transfer $\left(8.93 \times 10^{-4} \mathrm{cms}^{-1}\right)$ of nickel extraction decreased and became a plateau. This finding is probably due to the higher composition of palm oil in the liquid membrane phase, which increases the mass transfer resistance at the liquid membrane interface. It is strongly supported by the increased viscosity of LM from 13.5 to $18.7 \mathrm{cP}$ as the palm oil composition increased from 10 to $50 \%$, respectively. As the viscosity of LM increases, the diffusion coefficient of the membrane is inhibited, thus decreasing the extraction efficiency [27]. Such situation provides low permeability and mass transfer of solute ions through the membrane phase. Figure 11 shows the correlation of permeability values, which is directly proportional to the mass transfer values. However, Oschoa et al. [28] reported that mass transfer and permeability are contradict to the viscosity of the LM phase.

The flux of nickel extraction through the organic phases decreased from $9.75 \times 10^{-10}$ to $8.33 \times 10^{-10} \mathrm{molcm}^{-}$ ${ }^{2} \mathrm{~s}^{-1}$ with an increase in the composition of palm oil in the LM phase from $10 \%$ to $50 \%$, respectively. It is noteworthy that flux is inversely proportional to the viscosity of the LM phase. Hence, increasing the viscosity of LM decreases the flux of nickel permeation in the LM phase [29]. It can be concluded that the composition of palm oil is inversely proportional to the percentage of nickel extraction in SLM. From the simulation results, the optimum composition of palm oil was obtained at $10 \%$, leading to the highest permeability, mass transfer coefficient, and flux.

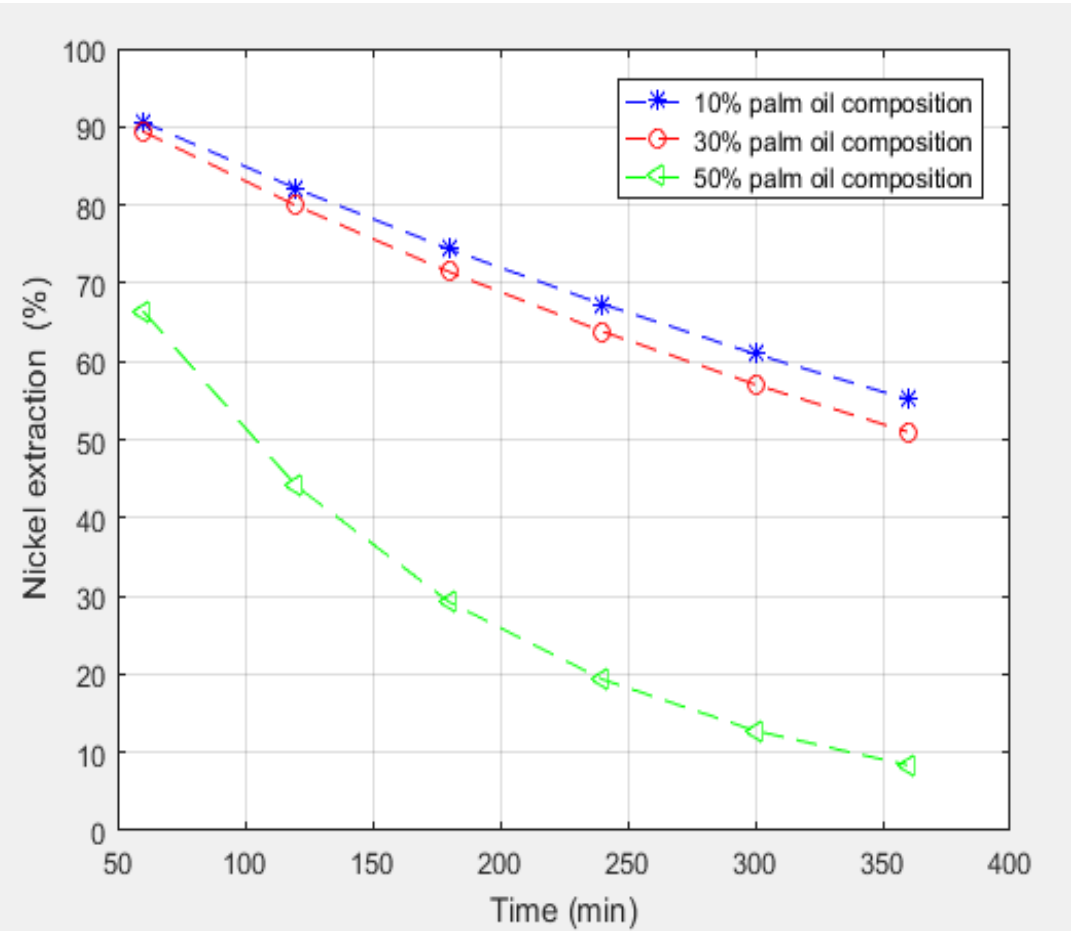

Figure 10. Effect of palm oil composition for simulation and experiment. 
Table 3 Variation of viscosity, permeability, flux with regard to the composition of palm oil in liquid membrane phase

\begin{tabular}{lllll}
.. & & & \\
Palm oil composition (\%) & Viscosity $(\mathrm{cP})$ & Permeability $\left(\mathrm{cms}^{-1}\right)$ & Mass transfer $\left(\mathrm{cms}^{-1}\right)$ & ${\text { Flux }\left(\mathrm{molcm}^{-2} \mathrm{~s}^{-1}\right)}^{-1.02 \times 10^{-3}}$ \\
\hline 10 & 13.5 & $1.36 \times 10^{-3}$ & $1.75 \times 10^{-10}$ & $9.72 \times 10^{-10}$ \\
30 & 15.4 & $1.19 \times 10^{-3}$ & $8.93 \times 10^{-4}$ & $8.33 \times 10^{-10}$ \\
50 & 18.7 & $1.19 \times 10^{-3}$ & $8.93 \times 10^{-4}$ & \\
\hline
\end{tabular}

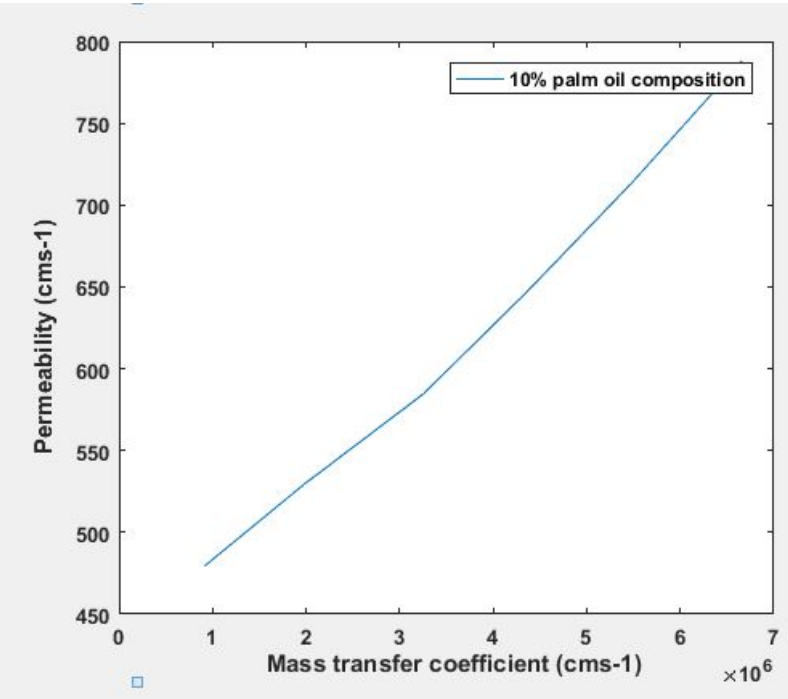

(a)

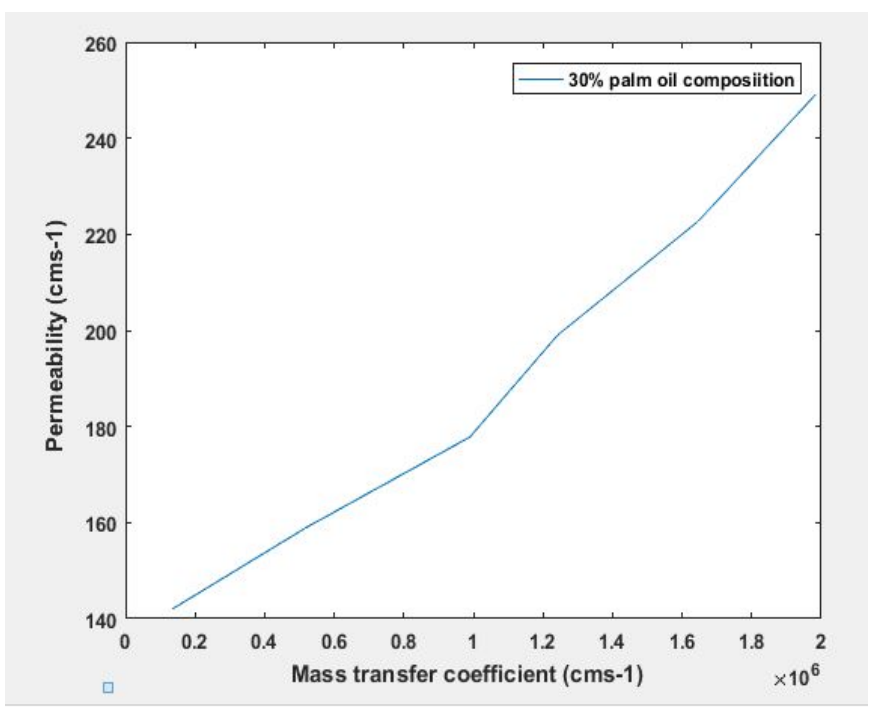

(b)

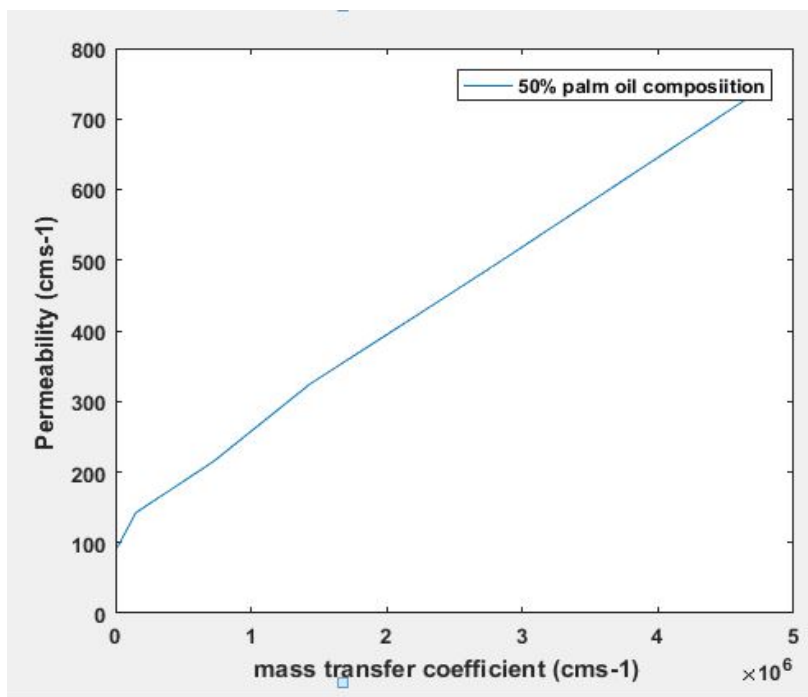

(c)

Figure 11. Correlation of permeability and mass transfer with regards to (a) $10 \%$, (b) $30 \%$ and (c) $50 \%$ of composition of palm oil in liquid membrane phase. 


\section{Conclusions}

The finding showed that the experimental data are correlated with the simulation results with $\mathrm{R}^{2}>0.90$. It can be concluded that the developed diffusion model is precise and feasible to predict the parameters influencing nickel transport efficiency through SLM. Out of the two parameters studied, the best conditions for SLM extraction of nickel were predicted at $100 \mathrm{ppm}$ nickel concentration and $10 \%$ palm oil composition in the liquid membrane phase with the maximum permeability, mass transfer, and flux of $1.36 \times 10^{-3} \mathrm{cms}^{-1}, 1.02 \times 10^{-3} \mathrm{cms}^{-1}$, and $9.75 \times 10^{-10} \mathrm{~mol} \mathrm{~cm}^{-2} \mathrm{~s}^{-1}$, respectively. Such abovementioned results revealed that the scientific data from modelling can predict the hypothetical data on the dynamic extraction of nickel via SLM. The model developed can offer better vision in the kinetic extraction of nickel in SLM. For future work, the prediction on effect of other operational parameters such as flow rate of aqueous feed phase and concentration of stripping agent can be investigated in the developed diffusion model to accurately optimize the extraction efficiency of nickel. On the other hand, besides of removal, recovery of nickel in SLM also can be investigated as well using this model.

\section{Conflicts of interest}

The author(s) declare(s) that there is no conflict of interest regarding the publication of this paper.

\section{Acknowledgments}

Grants from Universiti Teknologi Malaysia are acknowledged such as Professional Development Research University (PDRU) (Q. J130000.21A2.04E68), Q.J130000.21A2.05E51,Collaborative Research Grant (CRG 40.0) (Q. J130000.2451.08G02) and Collaborative Research Grant (CRG 40.1) (Q. J130000.2451.08G03).

\section{References}

[1] R. N. R. Sulaiman, N. Othman, N. F. M. Noah et al., "Removal of nickel from industrial effluent using a synergistic mixtures of acidic and solvating carriers in palm oil-based diluent via supported liquid membrane process," Chemical Engineering Research and Design, vol. 137, pp. 360-375, 2018.

[2] W. N. N. W. Omar and N. A. S. Amin, "Multi response optimization of oil palm frond pretreatment by ozonolysis," Industrial Crops and Products, vol. 85, pp. 389-402, 2016.

[3] Malaysia Environmental Quality Report (Industrial Effluent) Regulations (2009). Malaysian Department of Environment, P.U. (A) 434.

[4] R. N. R. Sulaiman and N. Othman, "Solvent extraction of nickel ions from electroless nickel plating wastewater using synergistic green binary mixture of D2EHPA-octanol system," Journal of Environmental Chemical Engineering, vol. 6, pp. 1814-1820, 2018.

[5] G. Rajivgandhi, Vimala RTV, N. Raju et al., "Adsorption of nickel ions from electroplating effluent by graphene oxide and reduced graphene oxides," Environmental Research, Article ID 111322, 2021.

[6] P. K. Parhi, "Supported liquid membrane principle and its practices: A short review," Environmental Research, vol. 2013, Article ID 618236, 2013.

[7] N. M. Kocherginsky, Q. Yang, L. Seelam," Recent advances in supported liquid membrane technology," Separation and Purification Technology, vol. 53, pp.171-177, 2007.

[8] A. Hachemaoui and K. Belhamel," Simultaneous extraction and separation of cobalt and nickel from chloride solution through emulsion liquid membrane using Cyanex 301 as extractant," International Journal of Mineral Processing, vol. 161, pp. 7-12, 2017.

[9] F. J. Alguacil, A. Coedo, M. Dorado et al., "Phosphine oxide mediate transport: modelling of mass transfer in supported liquid membrane transport of gold (III) using Cyanex 923," Chemical Engineering Sciences, vol. 56, pp. 3115-3122, 2001

[10] K. S. Kim, S. J. Choi, S. K. Ihm, "Simulation of phenol removal from wastewater by liquid membrane emulsion," Industrial Engineering Chemistry Fundamental, vol. 22, pp. 167-72, 1983.

[11] F. J. Alguacil and M. Alonso, "Description of transport mechanism during the elimination of copper (II) from wastewaters using supported liquid membranes and Acorga M5640 as carrier," Environmental Sciences Technology, vol. 39, pp. 2389-2393, 2005.

[12] A. Kaya, C., Onac, H. K. Alpoguz, "A novel electro-driven membrane for removal of chromium ions using polymer inclusion membrane under constant D.C. electric current," Journal of Hazardous Materials, vol 317, pp. 1-7, 2016.

[13] H. Ur Rehman, G. Akhtar, H. Ur Rashid, N. Ali, I. Ahmad, S. Ur Rehman, K. Khan, M. Arshad," Transport of Zn (II) by TDDA-Polypropylene Supported Liquid Membranes and recovery from waste discharge liquor of 
galvanizing plant of Zn (II)', Journal of Chemistry, vol 11, pp. 1-9, 2017.

[14] Tan Guan Ming, "Estimation of phenol removal from wastewater using diffusion model in supported liquid membrane, Degree. Thesis. Universiti Teknologi Malaysia; 2018.

[15] P. Kandwal, S. Dixit, S. Mukhopadhyay et al., "Mathematical modeling of $\mathrm{Cs}(\mathrm{I})$ transport through flat sheet supported liquid membrane using calix-[4]-bis(2,3-naptho)-18-crown-6 as the mobile carrier, "Desalination, vol 278, pp. 405-411, 2011.

[16] C. Zidi, R. Tayeb, M. B. S. Ali et al, "Liquid-liquid extraction and transport across supported liquid membrane of phenol using tributyl phosphate, "Journal of Membrane Science, vol. 360, pp. 334-340, 2010.

[17] R. N. R. Sulaiman and N. Othman, "Synergetic facilitated transport of nickel via supported liquid membrane process by a mixture of $\mathrm{Di}$ (2-ethylhexyl) phosphoric acid and n-octanol: Kinetic permeation study and approach for a green process, "Chemical Engineering and Processing- Process Intensification, vol.134, pp. 9-19, 2018.

[18] A. Sastre, A. Madi, J. L. Cortina et al. "Modelling of mass transfer in facilitated supported liquid membrane transport of gold (III) using phospholene derivatives as carriers, "Journal of Membrane Science, vol 139, pp. 57-65, 1998.

[19] M. E. M. Perez, J. A. Reyes-Aguilera, T. I. Saucedo et al. "Study of As (V) transfer through a supported liquid membrane impregnated with Trioctylphosphine oxide (Cyanex 921), "Journal of Membrane Science. vol 302, pp. 119-126, 2007.

[20] H. K. Haghighi, M. Irannajad, A. Fortuny et al., "Mathematical modeling for facilitated transport of Ge (IV) through supported liquid membrane containing Alamine 336, "Chemical Papers, vol 72, pp. 955-970, 2017.

[21] A. Abdelrasoul, H. Doan, A. Lohi et al., "Mass transfer mechanisms and transport resistances in membrane separation process, "Mass Transfer - Advancement in Process Modelling, Chapter: 2 Publisher: Intech Open, 2005.

[22] S. H. Chang, "Vegetable oil as organic solvent for wastewater treatment in liquid membrane processes, "Desalination and Water Treatment, vol. 52, pp. 88-101, 2014.

[23] K. Chakrabarty, P. Saha, A. K. Ghoshal, "Separation of mercury from its aqueous solution through supported liquid membrane using environmentally benign diluent, "Journal of Membrane Science, vol. 350, pp. 395-401, 2010.

[24] N. Othman, L. C. Heng, N. F. M. Noah et al, "Removal of Phenol from Wastewater by Supported Liquid Membrane Process, "Jurnal Teknologi, vol. 74, pp. 117-121, 2015.

[25] M. Chakraborty, C. Bhattacharya, S. Datta, "Effect of drop size distribution on mass transfer analysis of the extraction of nickel (II) by emulsion liquid membrane, "Colloids and Surfaces A: Physicochemical and Engineering Aspects, vol. 224, pp. 65-74, 2003.

[26] X. J. Yang, A. G. Fane, K. Soldenhoff, "Comparison of Liquid Membrane Processes for Metal Separations: Permeability, Stability, and Selectivity, "Industrial \& Engineering Chemistry Research, vol. 42, pp. 392-403, 2003.

[27] P. Dzygiel and P. P. Wieczorek, "Chapter 3- Supported Liquid Membranes and Their Modifications: Definition, Classification, Theory, Stability, Application and Perspectives, "Liquid Membranes, pp. 73-140, 2010.

[28] J. Alberto Ochoa, S. Whitaker, P. Stroeve, "Determination of Cell Membrane Permeability in Concentrated Cell Ensembles, "Biophysical Journal, vol. 52, pp. 763-774, 2002.

[29] F. J. Alguacil, M. Alonso, F. A. Lopez, "Active transport of cobalt (II) through a supported liquid membrane using the mixture DP8R and Acorga M5640 as extractant, "Desalination, vol. 281, pp. 221-225, 2011. 